The course and outcome of pregnancy was not correlated with the serum HCG value. The mean concentrations in 29 patients admitted once $(35.9 \pm 2.8 \mathrm{IU} / \mathrm{ml})$ and 13 patients admitted twice or more $(33.4 \pm 3 \cdot 1 \mathrm{IU} / \mathrm{ml})$ were similar. Moreover, individual values in patients with subsequent spontaneous abortion (three cases) or preterm delivery (two) were not noticeably different from those in other patients (figure)

\section{Discussion}

Patients with hyperemesis gravidarum had serum HCG concentrations significantly higher than normal between seven and 14 weeks of gestation. Haemoconcentration could be ruled out because packed cell volume and potassium and sodium concentrations in the same samples were within normal limits.

Endocrine and emotional factors are often suggested as important in the aetiology of hyperemesis gravidarum. However, the secretion of adrenocorticotrophic hormone and cortisol" ; concentrations of growth hormone, prolactin, and pituitary gonadotrophins ${ }^{12}$; and progesterone and oestrogens concentrations as reviewed by Fairweather, ${ }^{3}$ were similar in vomiting and non-vomiting women. Furthermore, attitudes to pregnancy, delivery, marriage, family, children, and spouse showed no difference between healthy and vomiting women. ${ }^{13}$ We cannot be certain whether the high concentration of HCG in serum is a primary factor in the aetiology of hyperemesis gravidarum or a secondary change. The association of HCG and hyperemesis gravidarum is supported by the observation that hyperemesis gravidarum begins concomitantly with the rising concentration of HCG; maximum values occur at 10-12 weeks of gestation, when hyperemesis is most common. We postulate that the hypothalamic vomiting centre is sensitive to $\mathrm{HCG}$ and that vomiting begins when the individual vomiting threshold concentration of HCG is reached.

The kit used for measuring the $\beta$-subunit of HCG was provided by courtesy of NIAMDD, National Institutes of Health, Bethesda, Md, USA.

\section{References}

${ }^{1}$ Landesman, R, and Saxena, B B, Fertility and Sterility, 1976, 27, 357.

Saxena, B B, and Landesman, R, American fournal of Obstetrics and Gynecology, 1978, 131, 97.

${ }^{3}$ Fairweather, D V I, American fournal of Obstetrics and Gynecology, 1968, $102,135$.

4 Schoeneck, F J, American Fournal of Obstetrics and Gynecology, 1942, 43, 308.

${ }^{5}$ Föllmer, W, Zentralblatt für Gynäkologie, 1964, 86, 947.

${ }^{6}$ Bandstrup, E, Fournal of Obstetrics and Gynaecology of the British Empire, 1939, 46, 700 .

${ }^{7}$ Fairweather, D V I, and Loraine, J A, British Medical Fournal, 1962, $1,666$.

8 Brindeau, A, Hinglais, H, and Hinglais, M, Comptes Rendus des Séances de la Société de Biologie, 1937, 124, 349.

9 Vaitukaitis, J L, Braunstein, G D, and Ross, G T, American fournal of Obstetrics and Gynecology, 1972, 113, 751.

${ }^{10}$ Herrera, L, Fournal of Laboratory and Clinical Medicine, 1958, 52, 34.

${ }^{11}$ Kauppila, A, et al, British Fournal of Obstetrics and Gynaecology, 1976, $83,11$.

12 Ylikorkala, O, Kauppila, A, and Haapalahti, J, British fournal of Obstetrics and Gynaecology, 1976, 83, 528.

13 Bernstein, I C, Minnesota Medicine, 1972, 35, 34.

(Accepted 8 May 1979)

\title{
Reduction of catheter-associated sepsis in parenteral nutrition using low-dose intravenous heparin
}

\author{
M J BAILEY
}

\section{Introduction}

The commonest serious complication of parenteral feeding is infection associated with the indwelling central venous cannula, ${ }^{1}$ the reported incidence of infection of the catheter tip varying from $0 \%$ to $41 \% .^{23}$ While this may be minimised by using a careful, aseptic technique when inserting the cannula, regularly inspecting the entry site into the skin, changing the giving set daily, and proscribing the catheter as a route for giving or taking blood or administering drugs, occasional infections will still occur. ${ }^{4}$ As heparin given via a peripheral venous cannula at a dose of 1 unit $/ \mathrm{ml}$ of infusate reduces the incidence of thrombophlebitis associated with the cannula, I designed this trial to assess whether a reduction in catheter-associated sepsis could be achieved in patients receiving parenteral nutrition using a similar regimen.

\section{Patients and methods}

I studied 80 consecutive patients who required intravenous feeding. The only criterion for entry into the trial was that I inserted or supervised the insertion of the central venous catheter. The catheter was inserted with full sterile precautions, the operator wearing a mask and sterile gloves. The skin was prepared with povidone-iodine solution, and the catheter when inserted was securely sutured to the skin to prevent movement at the entry site. The area of entry was then sprayed with povidone-iodine aerosol, covered with a sterile gauze 
dressing, and occluded with Sleek. The right subclavian route was used routinely to insert the catheter, and the position of the catheter tip was checked radiologically. The puncture site was examined on alternate days after insertion, unless a fever prompted earlier inspection. If the site was uninflamed the area was sprayed with povidone iodine and redressed; if it was inflamed (more than minimal local erythema) the catheter was removed as described below. The regimen for intravenous feeding was determined by the team in charge of the patient, but the following criteria were observed in all cases: (1) The central venous catheter was used solely to administer sterile intravenous fluids. Blood and blood fractions were given when necessary via a separate peripheral cannula. (2) Blood samples were not withdrawn from the catheter. (3) Drugs were not administered via the catheter, nor were any drugs added to the infusate after it left the pharmacy. (4) The giving set was changed daily.

Patients were randomly allocated into two groups on entering the trial. To each $500 \mathrm{ml}$ of intravenous fluid was added 500 units of heparin for patients in the treatment group and $0.5 \mathrm{ml}$ of physiological saline for patients in the control group, all additions being made under sterile conditions in the pharmacy. Only the pharmacy knew to which group each patient belonged.

Each central venous catheter was removed as follows. The dressing covering the puncture site was removed and a swab taken for culture where the catheter entered the skin. The whole area was then prepared with povidone-iodine solution, which was allowed to dry. The operator, wearing a mask and sterile gloves, removed the catheter and cut off the terminal $1 \mathrm{~cm}$ with sterile scissors, allowing the tip to fall into transport medium, which was then sent to the microbiology laboratory for culture. Indications for removal of the catheter were: (1) completion of treatment ("elective"); (2) appreciable inflammation around the puncture site; (3) pyrexia of over $37^{\circ} \mathrm{C}$ for more than 12 hours not accounted for by sepsis unrelated to the catheter (for example, chest or wound infection); (4) positive blood culture; and (5) mechanical failure. In all patients with temperature of $37^{\circ} \mathrm{C}$ or above at least three blood cultures were taken. Antibiotics were prescribed when clinically indicated, and patients who received antibiotics were not excluded from the trial. Catheters were not changed routinely unless one of the five conditions above was fulfilled.

\section{Results}

In 10 patients positive cultures were obtained from the catheter tip; one of these patients was in the treatment group and the remaining nine in the control group. Three of these nine control patients also had positive blood cultures, the same organism being isolated from the blood and the catheter. Table I shows the organisms isolated. The difference in the incidence of infection of the catheter tips in the two groups was significant $\left(\chi^{2}=7.3 ; P<0.01\right)$ but the difference in the numbers of positive blood cultures associated with infection of the

TABLE I-Details of organisms cultured at each site in 40 patients and 40 controls

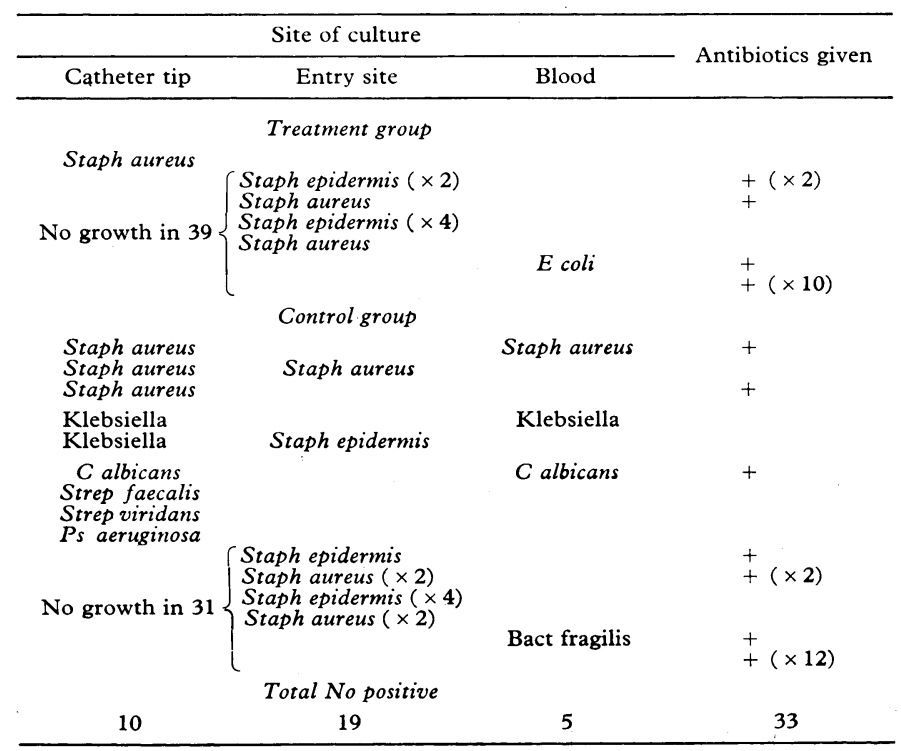

catheter tip $\left(x^{2}=3 \cdot 1, P=0.06\right)$ was not. Table II shows the reason for withdrawing the catheter and table III the initial indication for parenteral feeding. The mean duration of feeding was $7.9 \pm$ SD 4.9 days (range 3-27 days) in the treatment group and $6 \cdot 2 \pm 5 \cdot 1$ (range $2-24)$ days in the control group. Fourteen patients in the treatment group and 19 in the control group received antibiotics before culture. Of the 10 patients with positive catheter-tip cultures, three (all controls) received antibiotics.

TABLE II-Reason for removal of catheter. (Figures are numbers $(\%)$ of patients)

\begin{tabular}{|c|c|c|c|c|c|c|c|}
\hline & & & & & & $\begin{array}{l}\text { Treatment } \\
\text { group }\end{array}$ & $\begin{array}{l}\text { Control } \\
\text { group }\end{array}$ \\
\hline $\begin{array}{l}\text { Elective } \\
\text { Suspicion of sepsis }\end{array}$ & $\ldots$ & $\ldots$ & . & $\because$ & $\ldots$ & $\begin{array}{l}29(72.5) \\
10(25)\end{array}$ & $\begin{array}{l}18(45) \\
18(45)\end{array}$ \\
\hline Mechanical failure & $\because$ & $\because$ & $\because$ & $\because$ & $\because$ & $1(2 \cdot 5)$ & $4(10)$ \\
\hline
\end{tabular}

TABLE III-Reason for parenteral nutrition

\begin{tabular}{llllllcc}
\hline & & & & & $\begin{array}{c}\text { Treatment } \\
\text { group }\end{array}$ & $\begin{array}{c}\text { Control } \\
\text { group }\end{array}$ \\
\hline Postoperative nutrition $\ldots$ & $\ldots$ & $\ldots$ & $\ldots$ & $\ldots$ & $\ldots$ & 22 & 19 \\
Preoperative nutrition $\ldots$ & $\ldots$ & $\ldots$ & $\ldots$ & $\ldots$ & $\ldots$ & 5 & 8 \\
Gastrointestinal fistula $\ldots$ & $\ldots$ & $\ldots$ & $\ldots$ & $\ldots$ & $\ldots$ & 10 & 7 \\
Inflammatory bowel disease & $\ldots$ & $\ldots$ & $\ldots$ & $\ldots$ & $\ldots$ & 3 & 6 \\
\hline
\end{tabular}

\section{Discussion}

Cinefluoroscopy and postmortem studies have shown that a fibrin sleeve forms around indwelling polyethylene catheters after about 24 hours in situ. ${ }^{5}$ These sleeves were found at post-mortem examination when the catheter was dissected from the vein. The sleeve is usually dislodged when the catheter is removed in vivo, and thus in this study we could not determine whether the formation of such a sleeve occurred in the control group and was prevented in the treatment group. Several workers have noted that catheter-tip infection increases with the length of time the catheter remains in place, few infections being reported within 48 hours. This suggests that the formation of a fibrin sleeve may act as a first step towards bacterial colonisation of the catheter tip. It should be possible to prevent the formation of a fibrin sleeve by applying an anticoagulant locally at the catheter tip. Limited success has been achieved using catheters with heparin bonded to the polyethylene. ${ }^{5}$ Tanner et al showed that using low-dose heparin in the infusate with peripheral cannulae reduced thrombophlebitis and bacterial colonisation of the catheter tip, probably by inhibiting the fibrin sleeve. ${ }^{6}$

The series reported here shows an appreciable reduction in the incidence of catheter-tip infection after the addition of heparin at a dose of one unit per $\mathrm{ml}$ of infusate in patients receiving parenteral nutrition through a central venous catheter. None of the patients in the treatment group had positive blood cultures, but in three controls the same organism was isolated from the catheter tip and from blood sampled just before the catheter was removed. Only one catheter tip in the treatment group compared with nine in the control group was infected.

The lowest rates of catheter-associated sepsis are reported from units in which a team is specifically designated to manage the care of the catheter and other aspects of intravenous nutrition. ${ }^{7}$ Even with the scrupulous care and experience of such teams, infective complications still occur. Most centres do not have such a team, and infective complications are probably much more common. Infection of the catheter tip may occur in three ways-namely, via the infusate or giving set, from an infected puncture site, or by colonisation by blood-borne organisms. Strict adherence to the basic rules of catheter care can do much to eliminate infection occurring by the first two routes, but patients with an indwelling catheter remain at risk from bloodborne organisms. Many patients fed parenterally will be subject to transient bacteraemias, and possibly the presence of a fibrin 
sleeve at the catheter tip increases the likelihood of bacterial colonisation. Once such colonisation has occurred the catheter may act as a nidus for further blood-borne infection.

\section{References}

${ }^{1}$ Blackett, R L, et al, British fournal of Surgery, 1978, 65, 393.

${ }^{2}$ Wilmore, D W, and Dudrick, S J, Archives of Surgery, 1969, 98, 256.
${ }^{3}$ Durskin, M S, and Seigal, P D, fournal of the American Medical Association, 1963, 185, 966.

Copeland, F M, et al, Surgery, Gynecology, and Obstetrics, 1974, 138, 377.

s Horshal, V L, Ause, R G, and Hoskins, P A, Archives of Surgery, 1971, 102, 353.

- Tanner, W A, Delaney, T P, and Hennessy, T P, British fournal of Surgery, 1978, 65, 355.

${ }^{7}$ Ellis, B W, et al, British Medical fournal, 1976, 1, 1389.

(Accepted 2 May 1979)

\title{
Drug-induced oesophageal injury
}

\author{
F J COLLINS, H R MATTHEWS, S E BAKER, J M STRAKOVA
}

British Medical fournal, 1979, 1, 1673-1676

\section{Introduction}

Oesophageal injury due to accidental or suicidal ingestion of corrosives has long been recognised. Since 1970, however, it has become evident that certain therapeutic agents may also cause similar damage. ${ }^{1}$ A recent case of oesophageal ulceration caused by emepronium bromide (Cet:prin) at this hospital caused us to review reports of oesophageal injury from this and other drugs. Forty-one cases of oesophageal damage caused by eight different drugs were found with nine drug-related deaths. We review their clinical and pathological features in the hope of avoiding further instances of yet another iatrogenic disease.

\section{Case report}

In may 1977 a 15-year-old schoolgirl attended the medical outpatient clinic complaining of pain behind the sternum on swallowing. This had started suddenly about one month previously and had been very severe at first, so that even eating jelly had brought tears to her eyes. There had then been an improvement, but some pain still persisted. After the onset of symptoms she had been treated for one week with tetracycline but denied taking any other medications. At the age of 5 she had been investigated for mild unsteadiness on walking and early morning incontinence, but no neurological diagnosis had been reached and no treatment advised. There were no abnormal physical signs.

Investigations showed haemoglobin $13.6 \mathrm{~g} / \mathrm{dl}$, white cell count $6 \times 10^{9} / 1$, and ESR $15 \mathrm{~mm}$ in one hour. Chest radiograph was normal. Barium swallow showed no abnormality. In view of her symptoms rigid endoscopy was performed on 12 July under general anaesthesia. Severe circumferential mucosal ulceration was present with slough formation between 23 and $27 \mathrm{~cm}$ from the incisor teeth. The oesophagoscope could be passed through the area, and the distal oesophageal mucosa was found to be squamous and normal. Biopsy specimens from the ulcerated area showed non-specific acute and chronic inflammatory infiltrate with basal cell hyperplasia. In view of this unusual pathological appearance in the mid-oesophagus, she was questioned more carefully about drugs. It then emerged that since March 1977 she had been taking emepronium bromide, $200 \mathrm{mg}$ twice daily, prescribed by her doctor for her mild urinary incontinence. To investigate a possible connection between this drug and the oesophagitis certain specific studies were performed.

Queen Elizabeth Hospital, Edgbaston, Birmingham B15 2TH, UK F J COLLINS, MB, FRCSI, registrar in thoracic surgery H R MATTHEWS, MB, FRCS, consultant thoracic surgeon S E BAKER, BPHARM, MPS, staff pharmacist

J M STRAKOVA, MD, clinical assistant in thoracic surgery
On 27 July, while taking the drug treatment, the patient was screened radiologically after swallowing a tablet of emepronium bromide $(200 \mathrm{mg})$ that had been rendered radio-opaque by drilling the surface and filling the hole with barium sulphate. This was swallowed dry, as was her normal practice, and was seen to pass to the level of the aortic arch, where it became impacted (fig 1). Twenty minutes later the tablet was still at the same level, and it did not move until liquid barium was administered. Later, oesophageal mannometry studies were undertaken with the patient off the drug and then again two days

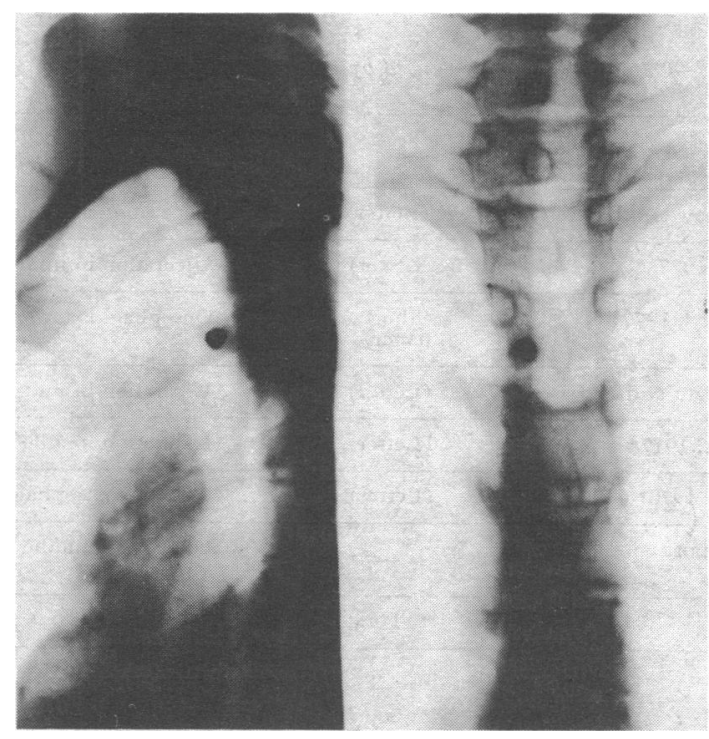

FIG 1-Tablet of emepronium bromide impacted in oesophagus just above aortic arch.

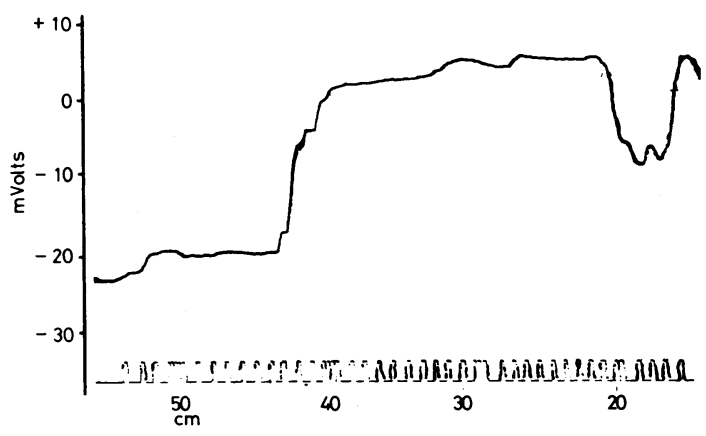

FIG 2-Mucosal potential difference while not taking drug; withdrawal from stomach to pharynx (left to right). Trace shows a stable level throughout body of oesophagus. 